AARP INTERNATIONAL THE JOURNAL

VOLUME $11-2018$ EDITION

AARP

Real Possibilities

\title{
Identifying Policies and Best Practices to Reduce Inequality in Later Life
}

By Angel Gurría 


\title{
Identifying Policies and Best Practices to Reduce Inequality in Later Life
}

\author{
By Angel Gurría
}

$P$

opulation aging will be fast, marked, and constant. While there are about 28 people ages 65 and over for every 100 people of working age in OECD countries today, this number is expected to rise to close to 50 within the next 35 years. From labor markets to health systems, the aging demographics will deeply affect the way society works and alter many aspects of our lives. Pensions are among the most directly affected areas. Already today the financial sustainability of retirement systems is a major concern in OECD countries and there is little doubt that the topic will rise further on policy agendas. Many governments have already started to tackle the problem, often by cutting pension benefits or increasing retirement ages, but further policy action will be needed in the future to ensure sustainable pensions in the long run.

In parallel to population aging, inequality is also on the rise. In the United States, like in many other countries, inequality has been growing from one generation to the next and old-age inequality will almost certainly increase among future retirees. This will likely lead to higher old-age poverty. Pover- ty among older persons in the United States is already a challenge today more than 20 percent of those over 65 have income under the poverty line, compared with less than 13 percent on average in OECD countries.

The OECD has stepped up its research efforts to identify ways of preventing this unequal aging, recognizing that a lower level of inequality is both an end in itself and a way of increasing countries' resilience to the consequences of demographic change. As a part of the OECD's inclusive growth agenda, the report Preventing Ageing Unequally and the forthcoming report Working Better with Age and Fighting Unequal Ageing in the United States document how disadvantages in education, employment, and health lead to deeply entrenched inequalities. Determined and well-tailored policy action is needed to achieve greater inclusiveness for people in later life while making sure that pension spending does not become an unsustainable financial burden for society.

Unfortunately, there is no simple or universally valid policy tool to ensure adequate and affordable pensions and avoid old-age disparities. Fighting unequal aging requires comprehensive, coherent, and sometimes complicated policy packages based on three main principles: policies must aim to prevent inequalities before they cumulate, mitigate existing inequalities while it is still possible, and cope with inequalities at older ages when it is too late to address their root causes.

Particularly promising are policies that start early in life and prevent inequalities before they build up. Tackling early school drop-out, for instance, especially in the case of disadvantaged children, has proved to generate substantial and long-lasting payoffs. Countries should place early-life interventions at the top of their policy agendas, as childhood circumstances affect numerous aspects of later life, from career progression to pensions. When more children attain a high level of education, more of them end up in high-quality jobs, earn higher wages, contribute more to the retirement system, and have access to adequate pensions in later life.

In addition to preventive measures, governments also need to take policy action to target existing inequalities in order to mitigate them and prepare 


\section{"Countries should place early-life}

interventions at the top of their policy agendas, as childhood circumstances affect numerous aspects of later life, from career progression to pensions.”

countries for the upcoming demographic challenges. Health inequalities are among the most striking forms of inequality and should be addressed urgently. In the United States, for example, highly educated 25 -year-old men can be expected to live more than seven years longer than their lower-educated peers. Lower socioeconomic groups are also much more likely to suffer from a certain number of diseases, develop disabilities, and depend on long-term care at older ages. Lifestyles and access to health care vary largely across population groups both within and across countries. Unhealthy people are less productive at work, face a higher risk of losing their jobs, and tend to retire earlier. Promoting healthy aging in general but especially among vulnerable groups, through multisectoral active-aging strategies and equal access to health care, must be a policy priority. Cost-effective prevention, primary care, and screening, among other services, should be provided at low or no cost to prevent diseases and encourage early detection of severe conditions such as cancer.

Governments must aim to foster broader access to employment opportu- nities and promote longer working lives. In the United States, employment rates at older ages are relatively high, at 62 percent for 55-64-year-olds versus 59 percent on average in OECD countries in 2016. However, there are large disparities across population groups. Early retirement remains a widespread phenomenon, often as soon as Social Security benefits become available at age 62 . Providing equal opportunities for workers to upgrade their skills throughout their working lives is a key prerequisite to fostering employment, especially in times of quick digitalization and automation. In the past, workers could expect to have only a few job changes during their career. In the future, workers will switch jobs more often or at the least carry out frequently changing professional tasks. Upgrading and adapting skills is crucial for employment and earnings prospects, especially among older workers. In addition, starting working life with the right skills is very important and improving vocational training for young adults with poorer skills proficiency is a key challenge. Without action, the prospects of future generations of older workers in the United States will be harmed.

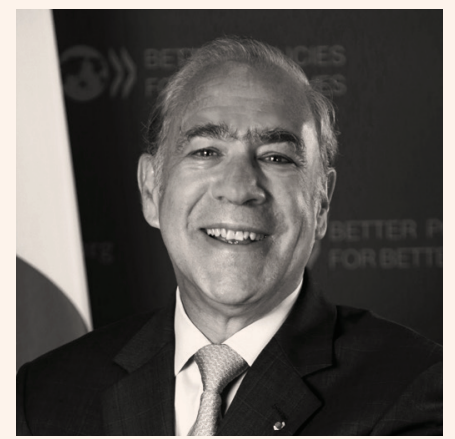

Angel Gurría SECRETARY-GENERAL ORGANISATION FOR ECONOMIC COOPERATION AND DEVELOPMENT (OECD) 


\section{Income Inequality in Old Age}

Gini coefficient, 2014 or latest year

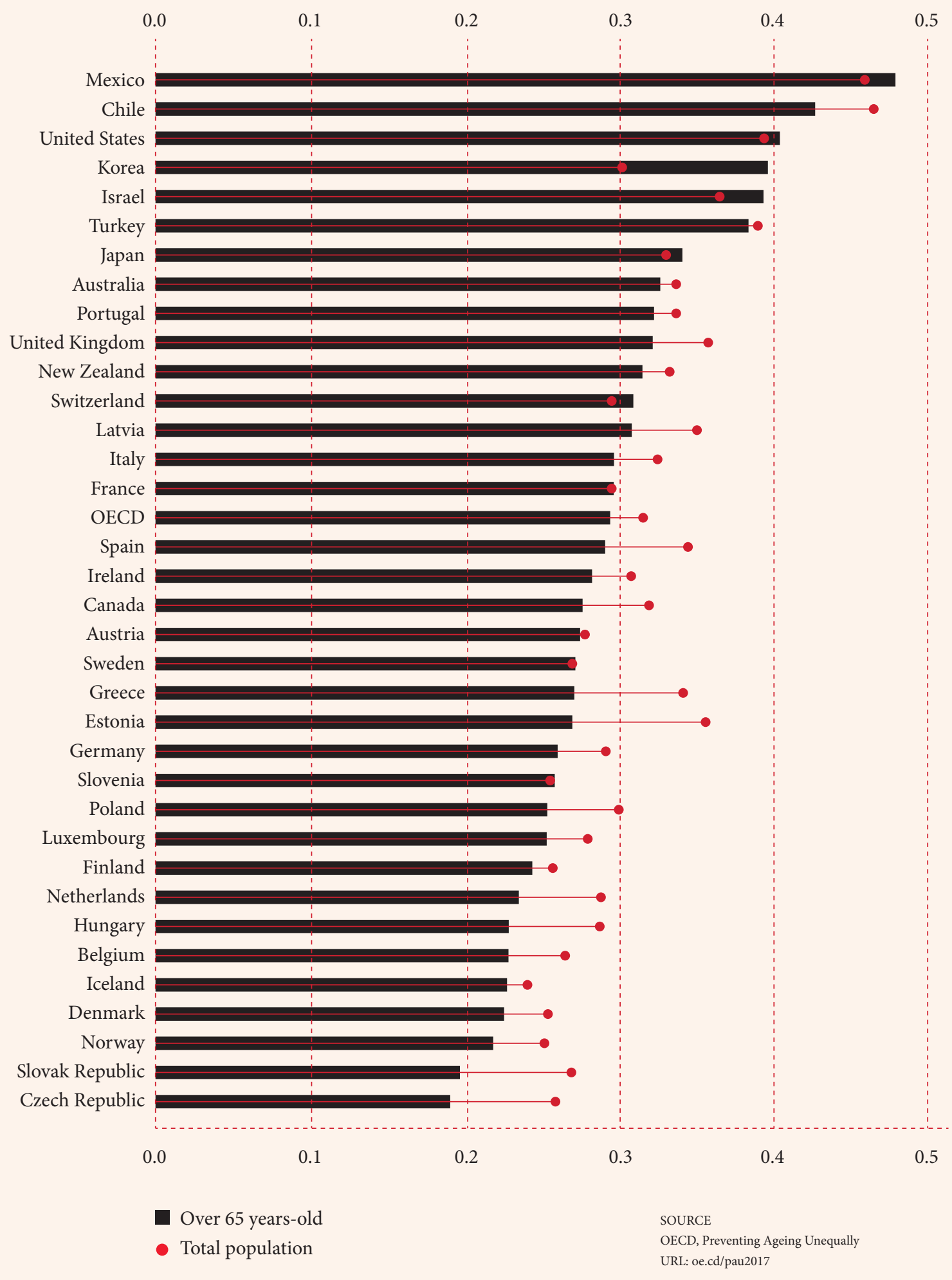




\section{Evolution of Income Inequality Over a Lifetime}

Estimated age pattern using Gini index of income

Reference age group $=20-34$

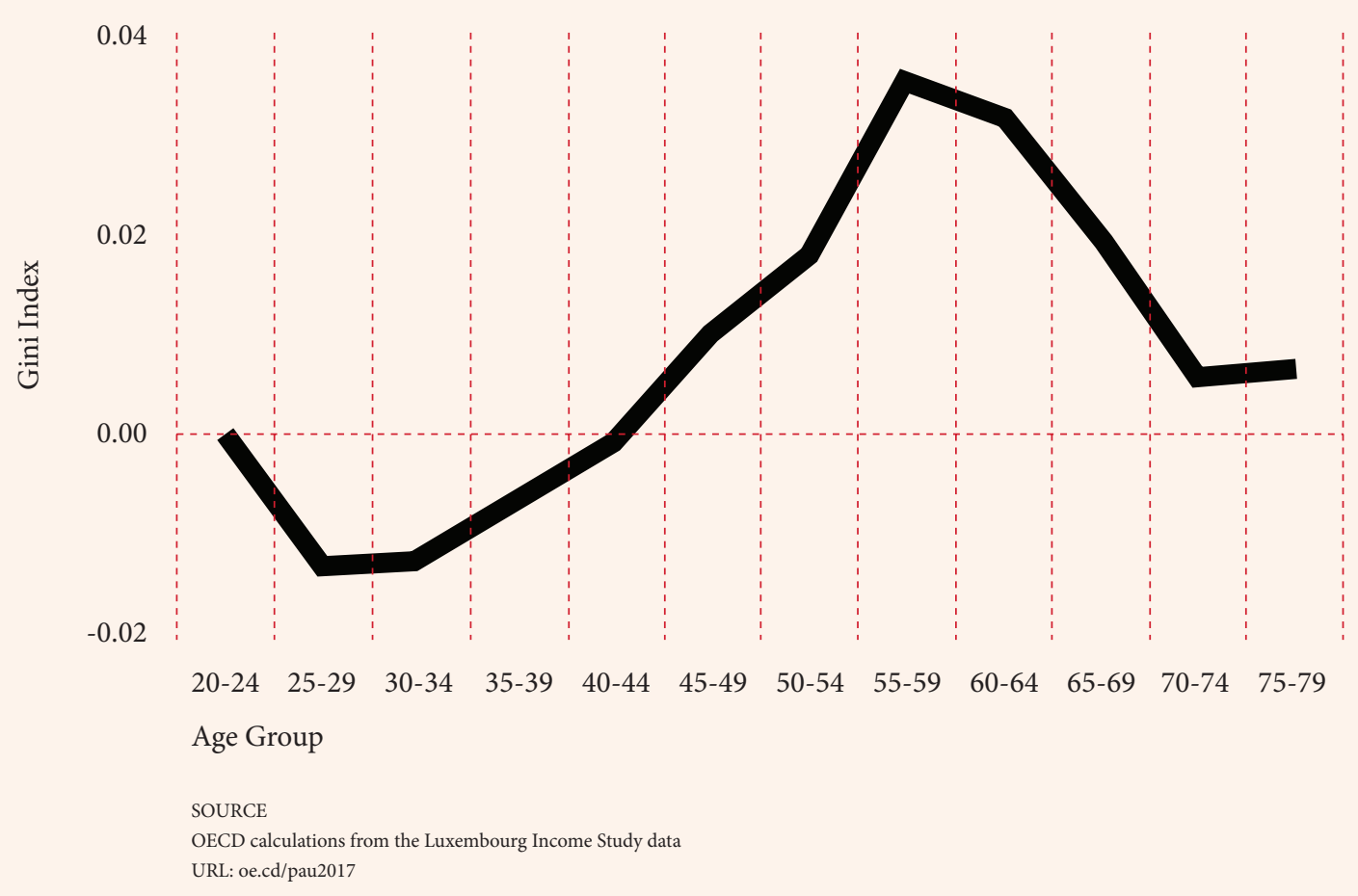

When it is too late to prevent or correct inequalities, a third strand of policies has to step in to prevent old-age poverty. Most important, pensions and social assistance have to be set at sufficient levels to avoid financial and material deprivation of older people, considering that low-income workers are also less likely to have made additional savings throughout their lives or to benefit from employer-provided private pension arrangements. In the United States, Social Security and Supplemental Security Income provisions are relatively low compared with those in other countries.
At their current levels, they are unlikely to fully cushion the increasing poverty risks in the future.

Designing successful policy packages requires rethinking the way policy is made. The evidence on how inequalities compound over the life cycle calls for joint action by ministries and agencies responsible for family, education, health and employment policies at different levels of government. Facilitating information and knowledge sharing between administrations and agencies is one important way of reducing the cost burden of delivering support, in the short term and in the long term. Countries will differ in the way such knowledge sharing and joint policy action are best set up, but all will need strong leadership in identifying needs, acting on them with appropriate policies, and coordinating policy responses between the different actors. The OECD is working closely with the United States, our member countries, and key partners in providing support to achieve these goals. 
AARP International engages global stakeholders to spark solutions that strengthen communities, protect the vulnerable and enable people around the world to pursue their goals and dreams. Working with governments, civil society and the private sector, we are focused on enhancing the quality of life for people as they age. We serve as the global voice for AARP, a social change organization with a membership of more than 37 million.

THE JOURNAL ONLINE

aarpinternational.org/journal

AARP INTERNATIONAL ONLINE

aarpinternational.org

FACEBOOK

facebook.com/aarpintl

TWITTER

@aarpintl

CONTACT

AARP International

601 E Street, NW

Washington, DC 20049

United States

T +1 2024342398

E international@aarp.org

AARP International: The Journal is a publication of AARP. The views expressed herein do not necessarily represent policies of AARP and should not be construed as endorsements. The mention of a product or service herein is solely for information to our readers and may not be used for any commercial purpose. AARP, which was established in 1958, is a nonprofit, nonpartisan organization with tens of millions of members ages 50 and older. State offices are located in all 50 states, the District of Columbia, Puerto Rico, and the Virgin Islands.

January 2018

()2018, AARP

Reprinting with permission only. 